ORIENTAL JOURNAL OF CHEMISTRY

An International Open Access, Peer Reviewed Research Journal

www.orientjchem.org
ISSN: 0970-020 X

CODEN: OJCHEG

2021, Vol. 37, No.(1):

Pg. 247-249

Brief communication

\title{
Study Rheological Behavior of Rapeseed oils Compared to Mineral oil
}

\author{
IOANA STANCIU \\ University of Bucharest, Faculty of Chemistry, Department of Physical Chemistry, \\ 4-12 Elisabeta Blvd, 030018, Bucharest, Romania. \\ ${ }^{*}$ Corresponding author E-mails: Istanciu75@ yahoo.com \\ http://dx.doi.org/10.13005/ojc/370135
}

(Received: January 04, 2021; Accepted: February 05, 2021)

ABSTRACT

This article presents the dependence of dynamic temperature viscosity and shear rate for rapeseed oils used as biodegradable lubricant and SAE 10W. The studied rheograms show the dependence of the dynamic shear rate viscosity as well as the dependence of the dynamic temperature viscosity. From the rheograms there is a decrease in the dynamic viscosity with temperature and shear rate for the two oils. The dynamic viscosity of rapeseed oil is most strongly influenced by the shear rate compared to the studied SAE 10W oil. The rheological behavior of rapeseed and mineral oil SAE 10W was studied with the Haake VT 550 viscometer at temperatures between 40 and $100^{\circ} \mathrm{C}$.

Keywords: Rheology, Mineral oil, Biodegradable

\section{INTRODUCTION}

One of the most difficult problem facing humanity today seems to be energy. Most of the energy comes from natural resources, such as natural gas, oil, coal, etc. Crude oil is the most important source of energy we have today, from which it is obtained: gasoline, diesel, kerosene, kerosene and other products used for locomotion and heating ${ }^{1}$. Increasing demand for fuel and irrational exploitation of deposits have led to depletion of oil reserves, generating supply gaps and fluctuating market prices ${ }^{2}$. Due to the depletion of crude oil resources and exhaust fumes from internal combustion engines and especially diesel engines, the interest in alternative fuels is growing today. Depletion of deposits and environmental degradation are realities that put strong pressure on companies and governments to improve the situation. From this perspective, the transition from fossil fuels to alternative ones is a great challenge of our age, and its realization can be done only with a thorough scientific research in which researchers from all fields involved participate.

Vegetable oils are considered alternative fuels because they can be easily regenerated and have diesel-like properties. Vegetable oils contain small amounts of mono- and diglycerides and free fatty acids. The advantages of vegetable oils are regenerability, biodegradability and the fact that the exhaust gases contain few harmful substances ${ }^{3}$.

This is an Open Access article licensed under a Creative Commons license: Attribution 4.0 International (CC- BY). Published by Oriental Scientific Publishing Company @ 2018

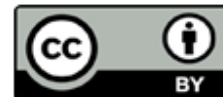


From the multitude of vegetable oils, rapeseed oil is important because it can be converted into biodiesel ${ }^{4}$, mixed with diesel ${ }^{5}$ or injected as such into the engine ${ }^{6}$. The viscosity of vegetable oils can be reduced by: transesterification (alcoholization with short chain alcohols), pyrolysis (thermal cracking), dilution with less viscous liquid fuels (diesel or ethanol) and emulsification (microemulsification) with surfactants ${ }^{7}$.

This article presents the study of the rheological behavior of SAE $10 \mathrm{~W}$ oil compared to rapeseed oil used as a biodegradable lubricant ${ }^{8-12}$.

\section{MATERIAL AND METHODS}

The rheological behavior of rapeseed oil and SAE 10W oil was determined using a Hake VT 550 viscoester, at temperatures between 40 and $100^{\circ} \mathrm{C}$ over the entire range of shear speeds using the $\mathrm{HV}_{1}$ viscose sensor.

\section{RESULTS AND DISCUSSION}

Figures 1-3 show the dependence of the dynamic viscosity versus shear rate at temperatures $40^{\circ} \mathrm{C}, 50^{\circ} \mathrm{C}$ and $60^{\circ} \mathrm{C}$. As can be seen from the graphs, SAE $10 \mathrm{~W}$ oil has a higher viscosity at the temperatures at which it was studied, compared to rapeseed oil at the same temperatures. This is explained by the fact that SAE $10 \mathrm{~W}$ oil has the following chemical composition: $75 \%$ saturated hydrocarbons, $20.55 \%$ aromatic hydrocarbons and $4.42 \%$ resins have a higher viscosity.

The composition of rapeseed oil in acids is as follows: $61 \%$ oleic, $21 \%$ linoleic, $11 \%$-linoleic, $4 \%$ palmitic, $2 \%$ stearic and $0.01 \%$ erucic.

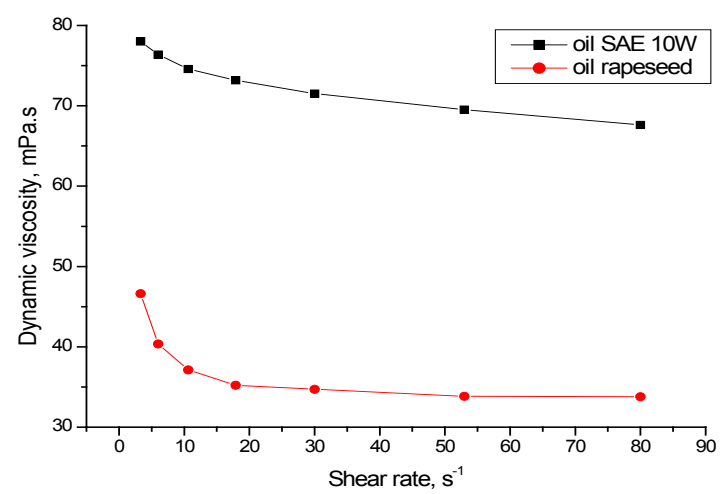

Fig. 1. The dependence $\eta$ versus $\gamma$ at temperatures $40^{\circ} \mathrm{C}$ for oil SAE 10W and oil rapeseed

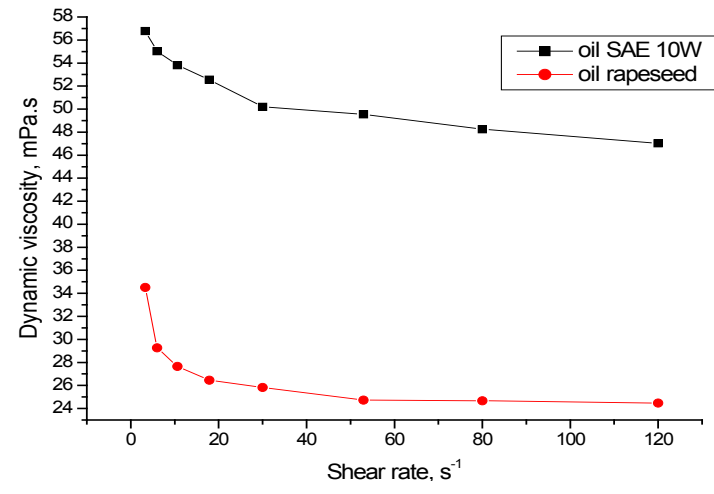

Fig. 2. The dependence $\eta$ versus $\gamma$ at temperatures $50^{\circ} \mathrm{C}$ for oil SAE 10W and oil rapeseed

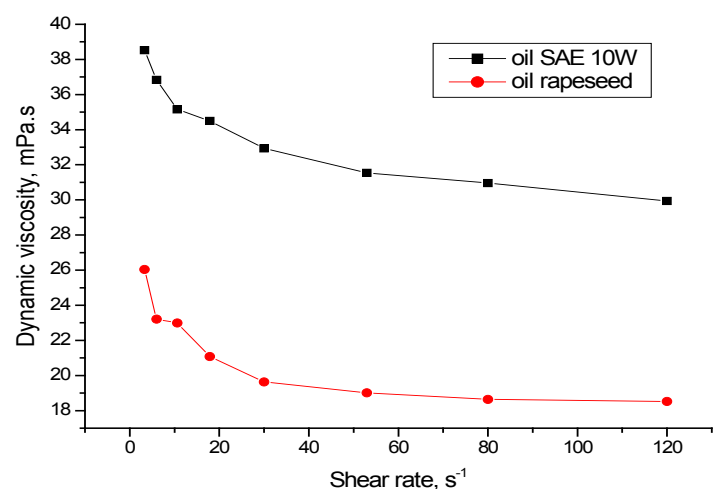

Fig. 3. Dependence $\eta$ versus $\gamma$ at temperatures $60^{\circ} \mathrm{C}$ for oil SAE 10W and oil rapeseed

Figures 4 and 5 show the temperature viscosity dependence with temperature for SAE 10W oil and rapeseed oil. There is a decrease in the dynamic viscosity with temperature for both SAE $10 \mathrm{~W}$ oil and rapeseed oil. In the two cases, straight lines with different spots are obtained at shear speeds of $3.3 \mathrm{~s}^{-1}$ and $6 \mathrm{~s}^{-1}$. SAE $10 \mathrm{~W}$ oil has a higher slope compared to rapeseed oil used in biodegradable lubricant ${ }^{13-16}$.

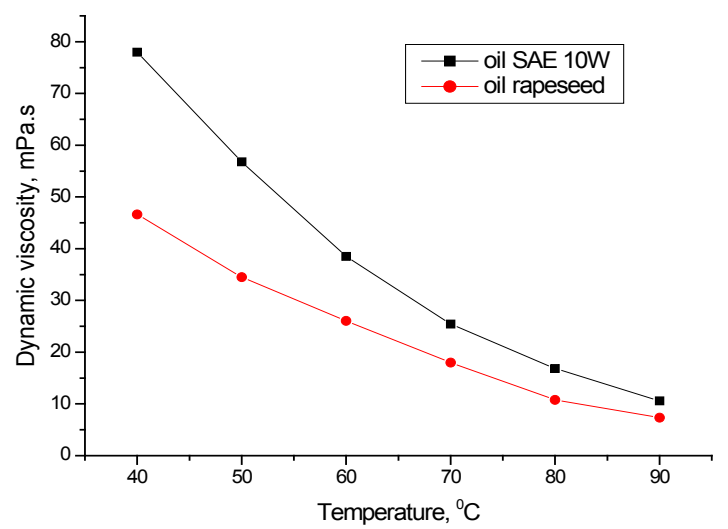

Fig. 4. The dependence $\eta$ versus $\mathrm{t}^{\circ} \mathrm{C}$ at shear rate $3.3 \mathrm{~s}^{-1}$ for oil SAE 10W and oil rapeseed 


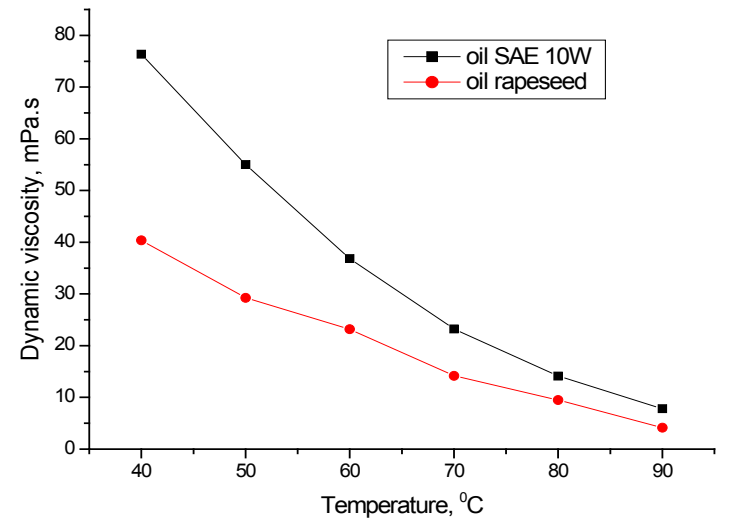

Fig. 5. The dependence versus $t^{\circ} \mathrm{C}$ at shear rate $6 \mathrm{~s}^{-1}$ for oil SAE 10W and oil rapeseed

The dynamic viscosities of both oils are strongly influenced by the shear rate and the temperature. At high shear rates the viscosities of both oils decrease less.

\section{CONCLUSION}

The dynamic viscosity of the two studied oils decreases with temperature and shear rate due to the fact that these oils have different chemical composition. For the analyzed oils, the dynamic viscosity of rapeseed oil is more strongly influenced by the shear rate compared to SAE 10W oil.

\section{ACKNOWLEDGMENT}

This research did not receive any specific grant from funding agencies in the public, commercial, or not-for-profit sectors.

\section{Conflicts of Interest}

The authors declare no conflict of interest.

\section{REFERENCES}

1. Stanciu I., Journal of Science and Arts., 2018 2(43), 443-458.

2. https://www.eia.gov/forecasts/steo/report/ prices.cfm. US Energy Information Agency, 12 februarie 2019.

3. Schwab A.W., Bagby M.O., Freedman B., Fuel., 1987, 66, 1372-1378.

4. Singh S.P.; Singh D., Renew Sust Energy Rev., 2010, 14, 200-216.

5. Labecki L.; Ganippa L.C., Fuel., 2012, 98, 15- 28.

6. Russo D.; Dassisti M.; Lawlor V.; Olabi A.G.; Renew Sust Energ Rev., 2012, 16, 4056-4070.

7. Neuma de Castro Dantas T.; da Silva A.C.; Neto A.A.D., Fuel., 2001, 80, 75-81.

8. Stanciu I., Oriental Journal of Chemistry., 2015, 31(3), 1383-1387.

9. Stanciu I., Oriental Journal of Chemistry., 2015, 31(4), 2017-2023.
10. Stanciu I, Ouerfelli N., Journal of Biochemical Technology., 2020, 3(11), 52-57.

11. Stanciu I., Analele Universitatii "Ovidius" Constanta-Seria Chimie., 2012, 23(1), 27-30.

12. Stanciu I.; A. Messaâdi A.; Díez-Sales O.; AlJameel S.S.; Mliki E.; Herráez J.V.; Ouerfelli N., Journal of Biochemical Technology., 2020, 3(11), 102-114.

13. Pratt C.J.; Newman A.P., \& Bond, P.C., Water Science and Technology., 1999, 39(2), 103-109.

14. Martins M.A.G., IEEE Electrical Insulation Magazine., 2010, 26(6), 7-13.

15. Masjuki H.H.; Maleque M.A.; Kubo A., \& Nonaka T., Tribology International., 1999, 32(6), 305-314.

16. Jin H.; Andritsch T.; Tsekmes I.A.; Kochetov R.; Morshuis P.H., \& Smit J.J., IEEE Transactions on Dielectrics and Electrical Insulation., 2014, 21(3), 1100-1108. 